\title{
Mid-infrared supercontinuum generation in soft-glass suspended core photonic crystal fiber
}

\author{
M. Klimczak • B. Siwicki • P. Skibinski - D. Pysz • \\ R. Stepien - A. Szolno - J. Pniewski - C. Radzewicz • \\ R. Buczynski
}

Received: 13 April 2013 / Accepted: 8 October 2013 / Published online: 18 October 2013

(C) The Author(s) 2013. This article is published with open access at Springerlink.com

\begin{abstract}
Supercontinuum from 800 to 2,600 $\mathrm{nm}$ has been obtained in a soft glass suspendedcore photonic crystal fiber. The fiber has been fabricated using an in-house synthesized, lead-bismuth-galate oxide glass (PBG-08), which has a transmission window from $500 \mathrm{~nm}$ to $4,500 \mathrm{~nm}$. Dispersion characteristic has been designed to enable efficient pumping in the anomalous regime, using typical telecommunication wavelengths and influence of discrepancy between design and physical dispersion profile of fiber is discussed. An optical parametric amplifier system seeded with a Ti:Sapphire oscillator has been used as a light source (70 fs pulses with $100 \mathrm{kHz}$ repetition rate). Supercontinuum bandwidth on the midinfrared side is limited by $\mathrm{OH}^{-}$absorption of the glass and presence of second zero-dispersion wavelength in the spectral area of interest. Flatness the spectrum remains under $7 \mathrm{~dB}$ from roughly $1,800 \mathrm{~nm}$ to about $2,500 \mathrm{~nm}$.
\end{abstract}

Keywords Supercontinuum generation - Suspended core photonic crystal fiber . Mid-infrared source $\cdot$ Nonlinear fiber optics

\section{Introduction}

Increasing number of applications in spectroscopy and life-sciences, as well as telecommunications, can benefit from broadband and compact sources of coherent radiation (Unterhuber et al. 2004; Kaminski et al. 2008; Swiderski and Maciejewska 2012). Supercontinuum sources based on silica photonic crystal fibers (PCF), operating in spectral

M. Klimczak $(\varangle) \cdot$ B. Siwicki · D. Pysz, · R. Stepien, · A. Szolno · R. Buczynski Institute of Electronic Materials Technology, Wolczynska 133, 01-919 Warsaw, Poland e-mail: mariusz.klimczak@itme.edu.pl

B. Siwicki · J. Pniewski - C. Radzewicz · R. Buczynski

Faculty of Physics, University of Warsaw, Pasteura 7, 02-093 Warsaw, Poland

P. Skibinski

Institute of Physical Chemistry, PAS, Kasprzaka 44/52, 01-224 Warsaw, Poland 
range from the visible to the near-infrared, have been already commercialized. Interest is now focused on supercontinua covering near-infrared/mid-infrared part of spectrum, where vibration bands of a number of important organic compounds are located (Waynant et al. 2001; Werle et al. 2002; Guo et al. 2004). Effective supercontinuum generation at wavelengths longer than $2,000 \mathrm{~nm}$ requires optical fibers with transmission in the mid-infrared. Supercontinuum generation in excess of 4,000 $\mathrm{nm}$ has been reported in step index fibers or suspended core photonic crystal fibers made of various multicomponent glasses, e.g. $\mathrm{ZBLAN}\left(\mathrm{ZrF}_{4}-\mathrm{BaF}_{2}-\mathrm{LaF}_{3}-\mathrm{AlF}_{3}-\mathrm{NaF}\right)$ (Agger et al. 2012), tellurite (eg. $75 \mathrm{TeO}_{2}-12 \mathrm{ZnO}-5 \mathrm{PbO}-3 \mathrm{PbF}_{2}-5 \mathrm{Nb}_{2} \mathrm{O}_{5}$ ) (Domachuk et al. 2008) and chalcogenide $\left(\mathrm{As}_{2} \mathrm{~S}_{3}\right)$ (Marandi et al. 2012). Usually, these glasses exhibit increased scattering losses (with exception of ZBLAN), which necessitates use of only short lengths of fiber for supercontinuum generation. In this situation fiber nonlinearity plays crucial role. Suspended core photonic crystal fibers (SC-PCF) are a relatively new class of fibers, in which ultra-confinement is achieved through specially designed microstructure (Dong et al. 2008). Resulting small effective mode area, typically in the order of several $\mu \mathrm{m}^{2}$, promotes relatively large values of nonlinear coefficient. This comes at a cost of lower coupling efficiency with fiber, due to very small core diameter. Literature reports on supercontinuum generation in suspended core fibers are less available, than for other types of photonic crystal fibers. Libin Fu et al. demonstrated octave spanning supercontinuum in silica photonic crystal fibers pumped at around 800 and 1,000 nm (Fu et al. 2008). Also in silica suspended core PCFs, Mergo et al. obtained nearly octave spanning supercontinua using as pump various wavelengths between 740 and $880 \mathrm{~nm}$ (Mergo et al. 2008). More recent reports were focused on suspended core PCFs drawn from different non-silica glasses, with transmission windows enabling midinfrared generation (Domachuk et al. 2008; El-Amraoui et al. 2010; Savelii et al. 2011, 2012). It is to be noted, that for photonic crystal fibers drawn from soft glasses, suspended core geometry enables reduction of thermal processing steps to the minimum, thus helping to avoid recrystallization of glass.

In this work, we report on supercontinuum generation in suspended core photonic crystal fiber, drawn from lead-bismuth-galate oxide glass, which was pumped with $70 \mathrm{fs}$ pulses at a wavelength of $1,500 \mathrm{~nm}$. Among mostly tellurite and chalcogenide compositions of glasses used for suspended core PCF drawing, our glass is a new selection for such a fiber. Yet it offers advantages, like higher mechanical durability and recrystallization resistance against tellurites, chalcogenides and fluorides, as well as relatively high nonlinear refractive index, which falls between the typical values reported for tellurite oxide glasses and chalcogenide glasses (Lorenc et al. 2008).

\section{Suspended core fiber development}

Demonstrated SC-PCF has been fabricated using stack and draw method at Institute of Electronic Materials Technology. The structure of fiber is shown in SEM images in Fig. 1. It consists of three large air channels, separated with thin struts supporting fiber core. Diameter of photonic microstructure of fiber is $54.3 \mu \mathrm{m}$, diameter of the core area is roughly $1.22 \mu \mathrm{m}$, and the struts are just $290 \mathrm{~nm}$ thick. Commercial mode solver (Lumerical Mode Solutions) has been used to determine modal properties of fiber, which does support several higher order modes, apart from the fundamental mode. Obtained thin and relatively long struts supporting the core ensure a high degree of isolation of the core area, which results in a negligible modal confinement loss for the fundamental mode. This allows to assume fiber loss for the 

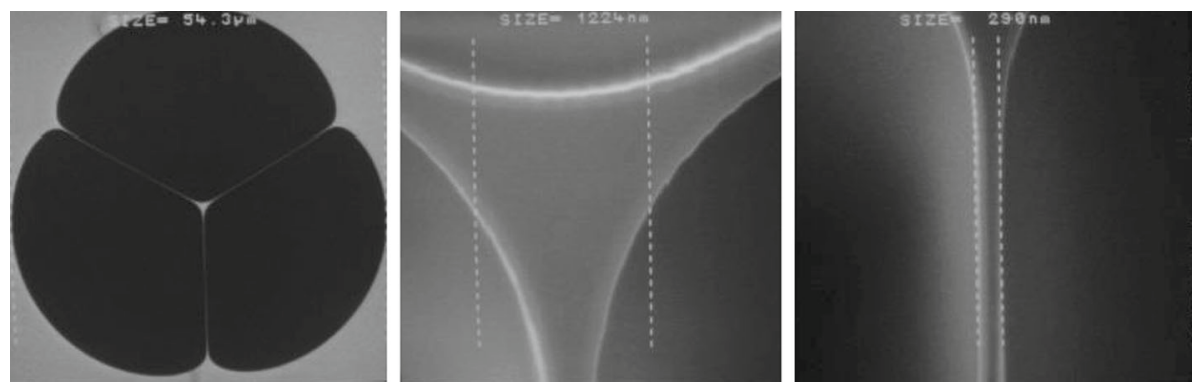

Fig. 1 SEM images of microstructure of developed suspended core photonic crystal fiber, seen left to right: overall view of microstructure $(\emptyset=54.3 \mu \mathrm{m})$, core area $\left(\emptyset_{\text {core }}=1.22 \mu \mathrm{m}\right)$, one of the struts supporting the core (thickness $\mathrm{d}=0.29 \mu \mathrm{m}$ )

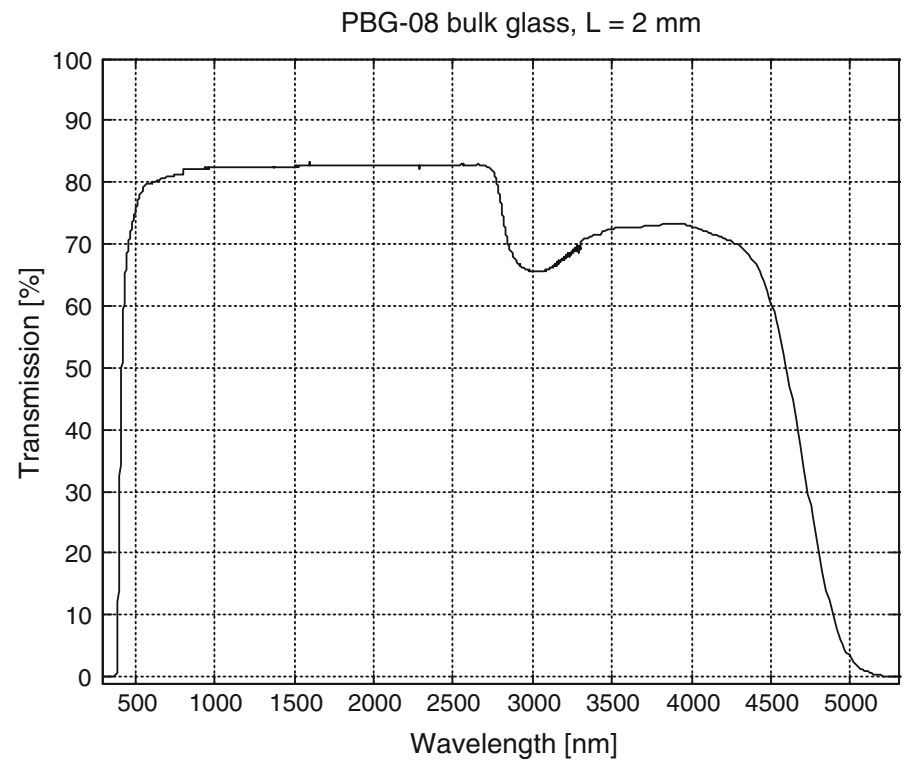

Fig. 2 Transmission characteristic of bulk lead-bismuth-galate oxide glass (PBG-08), measured with a $2 \mathrm{~mm}$ long sample

fundamental mode as roughly equal to loss resulting from glass attenuation. Its measured characteristic is presented in Fig. 2, for a $2 \mathrm{~mm}$ thick sample.

The glass oxide composition (weight \%), enabling fiber drawing without recrystallization, in this case is following: $\mathrm{PbO}: 39.17, \mathrm{Bi}_{2} \mathrm{O}_{3}: 27.26, \mathrm{Ga}_{2} \mathrm{O}_{3}: 14.26, \mathrm{SiO} 2: 14.06$ and CdO: 5.26. This glass has been successfully used for photonic crystal fiber development previously (Ertman et al. 2012; Stepien et al. 2012). The glass has one of the highest values of nonlinear refractive index among oxide based soft glasses, $\mathrm{n}_{2}=4.3 \times 10^{-19} \mathrm{~m}^{2} / \mathrm{W}$, measured with Z-scan method at 1,240 nm (Lorenc et al. 2008). We are not aware of any wavelength-dependent measurements of $\mathrm{n}_{2}$ for this type of glass, therefore we took a flat $\mathrm{n}_{2}$ value for calculation of nonlinear coefficient in our fiber. Together with calculated effective mode area of the fiber at around $4 \mu \mathrm{m}^{2}$, nonlinear coefficient at the used pump wavelength of 1,500 nm was relatively high for this fiber, $\gamma=\left(\omega_{0} \cdot \mathrm{n}_{2}\right) /\left(\mathrm{c} \cdot \mathrm{A}_{\mathrm{eff}}\right)=411 \mathrm{~W}^{-1} \cdot \mathrm{km}^{-1}$. Notably, the transmission window of the PBG-08 glass extends from about $500 \mathrm{~nm}$ up to over 

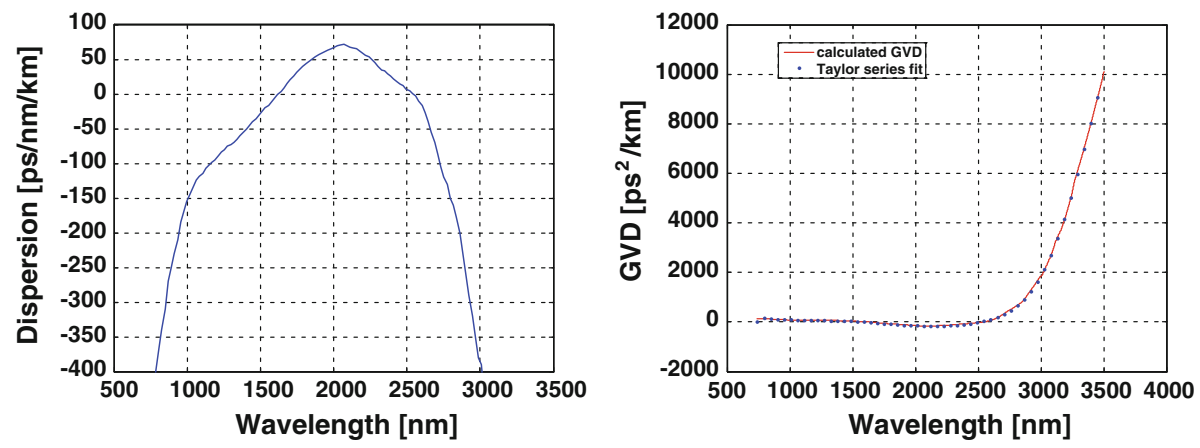

Fig. 3 Calculated dispersion of the developed fiber and its GVD characteristic along with Taylor series fit (fitting was much denser than shown)

Table 1 Taylor series expansion coefficients of GVD characteristic $\beta_{2}=-\lambda \cdot D /(2 \cdot \pi \cdot c)$, around pump wavelength of $1,500 \mathrm{~nm}$, used in supercontinuum numerical modeling

\begin{tabular}{lllll}
\hline$\beta_{2}\left[\mathrm{ps}^{2} / \mathrm{m}\right]$ & $\beta_{3}\left[\mathrm{ps}^{3} / \mathrm{m}\right]$ & $\beta_{4}\left[\mathrm{ps}^{4} / \mathrm{m}\right]$ & $\beta_{5}\left[\mathrm{ps}^{5} / \mathrm{m}\right]$ & $\beta_{6}\left[\mathrm{ps}^{6} / \mathrm{m}\right]$ \\
\hline $70.63 \times 10^{-3}$ & $-32.89 \times 10^{-6}$ & $-21.40 \times 10^{-7}$ & $28.37 \times 10^{-9}$ & $694.45 \times 10^{-12}$ \\
\hline$\beta_{7}\left[\mathrm{ps}^{7} / \mathrm{m}\right]$ & $\beta_{8}\left[\mathrm{ps}^{8} / \mathrm{m}\right]$ & $\beta_{9}\left[\mathrm{ps}^{9} / \mathrm{m}\right]$ & $\beta_{10}\left[\mathrm{ps}^{10} / \mathrm{m}\right]$ & $\beta_{11}\left[\mathrm{ps}^{11} / \mathrm{m}\right]$ \\
\hline$-87.73 \times 10^{-13}$ & $-243.51 \times 10^{-15}$ & $28.60 \times 10^{-16}$ & $79.35 \times 10^{-18}$ & $-849.57 \times 10^{-22}$ \\
\hline
\end{tabular}

$4,500 \mathrm{~nm}$, with a characteristic dip at about $3,000 \mathrm{~nm}$, which is related to $\mathrm{OH}^{-}$content in glass. $\mathrm{OH}^{-}$contamination does not decrease transmission to below $65 \%$ in the investigated sample, however, this translates to tens of $\mathrm{dB} / \mathrm{m}$ of attenuation in the drawn fiber. We believe this is the main reason for which obtained supercontinuum spectrum in this fiber does not extend further into mid-infrared, where absorption related to $\mathrm{OH}^{-}$ion impurities increases. Further improvements to glass synthesis are necessary to overcome this issue. $\mathrm{OH}^{-}$concentrations as low as $1 \mathrm{ppm}(0.1 \mathrm{~dB} / \mathrm{m}$ loss $)$ were recently reported in oxide tellurite glass fibers, where glass synthesis incorporated in-house purification of commercial raw materials, as well as replacement of $\mathrm{OH}^{-}$ions with fluorine ions (Savelii et al. 2013). Fiber sample used in our experiment was not end-capped. The reason for this was to avoid introducing additional coupling losses of pump pulses. We also believe, that ambient moisture has very little detrimental effect on this particular glass, once the fiber is drawn.

Dispersion characteristic of the developed fiber has been calculated based on previously predicted modal properties of fiber. The resulting profile is shown in Fig. 3 along with calculated group velocity dispersion characteristic (GVD) and its Taylor series expansion fit, used in numerical modeling. Dispersion of the developed fiber has two zero dispersion wavelengths (ZDW), the first one is at around 1,600 $\mathrm{nm}$ and at around 2,600 $\mathrm{nm}$. Taylor series coefficients for GVD fitting, taken around used pump wavelength of 1,500 nm, are given in Table 1.

\section{Measurement setup}

The measurement setup used in this study is presented in Fig. 4. It consisted of an in-house titanium sapphire oscillator, which seeded an OPA (Coherent OPA 9800), through a chirped 


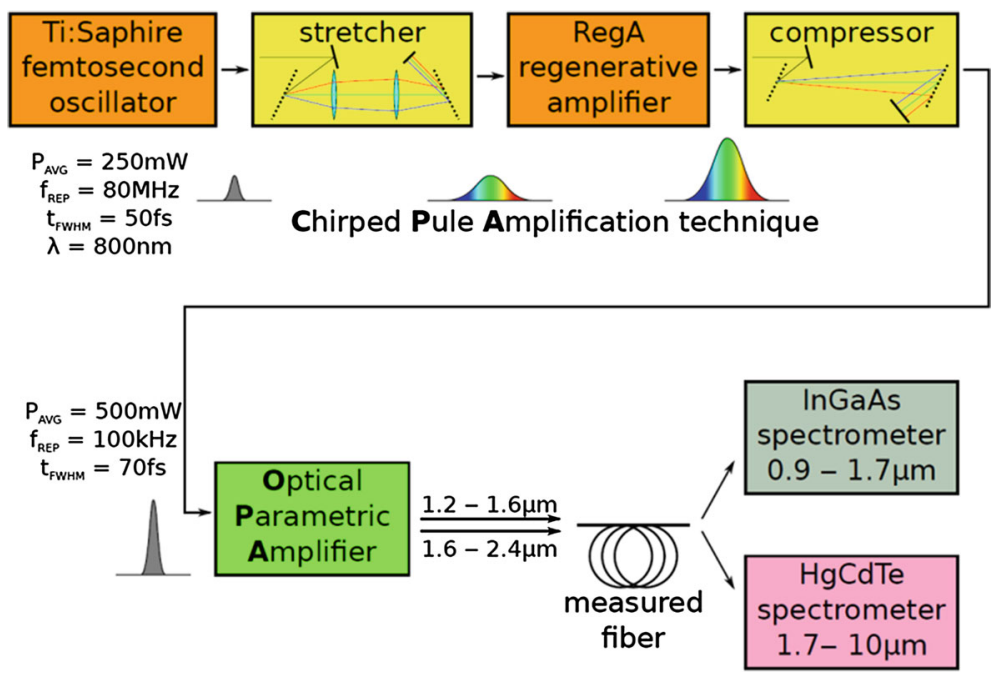

Fig. 4 Measurement setup used in this study

pulse amplification section comprising a pulse stretcher, a regenerative amplifier (Coherent RegA 9800) and a pulse compressor. Resulting pump pulses were $70 \mathrm{fs}$ long, with a $100 \mathrm{kHz}$ repetition rate and a maximum peak power of around $200 \mathrm{~kW}$. Largest peak power incident on the fiber input facet was attenuated down to $100 \mathrm{~kW}$ and coupling efficiency estimated by measurement of average power at the fiber output was up to $10 \%$. The generated supercontinuum spectra were dispersed on grating monochromators $(3001 / \mathrm{mm}$ grating) equipped with two different types of detectors, one for the near-infrared (InGaAs) and one for the mid-infrared (HgCdTe camera from Sofradir).

\section{Results and discussion}

Supercontinuum spectrum, recorded for the developed fiber under 1,500 nm pumping, is shown in Fig. 5 in a $20 \mathrm{~dB}$ dynamic range (solid trace), along with its numerical reconstruction. Zero dispersion wavelength of this fiber was located outside of tuning range of our pump source, that is at over $1,600 \mathrm{~nm}$. Hence, most effective pumping in the anomalous dispersion range of fiber in this study was not possible at this time. The fiber sample length used in the experiment was $5.5 \mathrm{~cm}$. Since characteristic nonlinear length scale calculated for this fiber was much shorter than its dispersive length scale $(0.3 \mathrm{~mm}$ against $7 \mathrm{~cm})$, we assumed the broadening should occur fast, ie. in the first few mm, up to $1 \mathrm{~cm}$ (Savelii et al. 2013; Dudley and Taylor 2010). Hence the sample length was a matter of cutting convenience. Pumping into normal dispersion, at a wavelength shorter than the first ZDW, results in a distinct dip in proximity of this ZDW and soliton generation at longer wavelengths in the anomalous dispersion. Experimentally recorded spectrum cuts off at about 2,600 nm, due to location of second zero dispersion wavelength in this area, followed by $\mathrm{OH}^{-}$absorption at longer wavelengths, which prevents generation of a dispersive wave. Dashed trace in Fig. 5 denotes numerical reconstruction of the measured spectrum for dispersion characteristic shown in Fig. 3. It was obtained by solving nonlinear Schrödinger equation (NLSE). Split Step Fourier Method (SSFM) and an algorithm based on the one proposed by Dudley and Taylor (2010) was used in this case. 


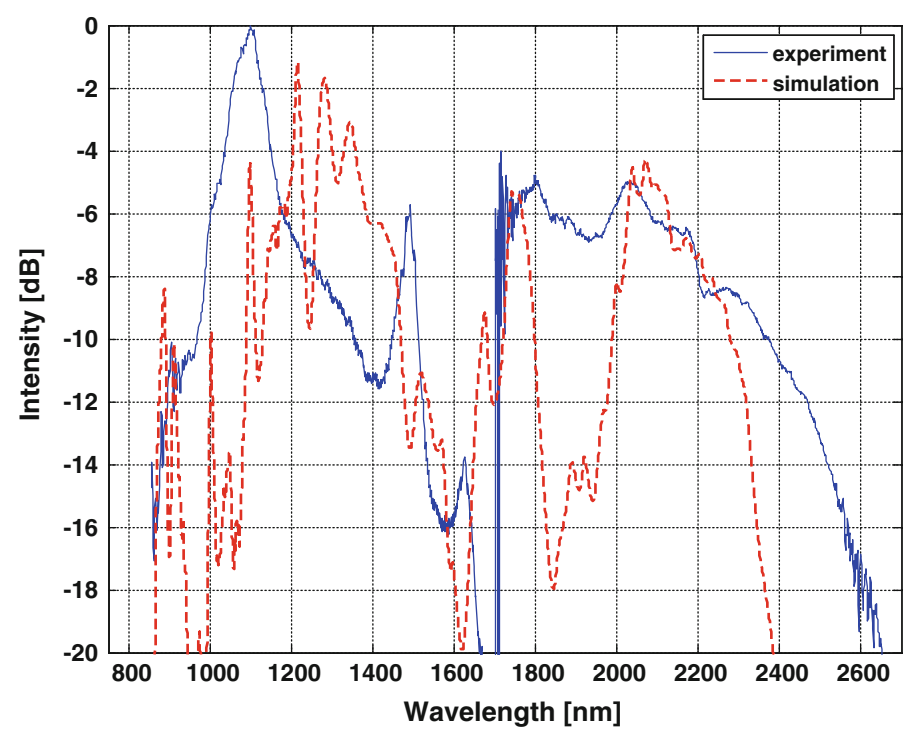

Fig. 5 Supercontinuum spectrum recorded experimentally (solid line) and reconstructed numerically (dashed line)

Model proposed in Dudley and Taylor (2010) was extended with inclusion of frequencydependent loss, measured for the fiber glass (Fig. 2), which most notably enables to take into account the $\mathrm{OH}^{-}$related cutoff of spectrum. Raman response of the fiber was based on measured Raman scattering spectrum in bulk PBG-08 glass (first order Raman shift at $29 \mathrm{THz}$ ), with Raman contribution to nonlinearity at $f_{R}=0.1$ yielding best accuracy of supercontinuum spectrum to measurement. There is a qualitative agreement of simulation with the experiment, where the main features of experimental spectrum are reproduced with relative accuracy. The observed discrepancies may be accounted for by uncertain dispersion profile of fiber. This concerns especially the long-wavelength edge of spectral range of interest. Material dispersion of the glass at longer wavelengths is uncertain. Waveguide dispersion at longer wavelengths is much more sensitive (than at shorter wavelengths) to geometric dimensions of the photonic structure of fiber, ie. the core diameter and thickness of struts. With this in mind, we attempted to reconstruct numerically the evolution of spectral broadening along the fiber length, which is shown in Fig. 6, together with corresponding, numerical spectrogram. As expected, the broadening begins with self-phase modulation, with solitons appearing in spectrogram when new wavelengths are generated across the short-wavelength ZDW. Four-wave mixing (FWM) phase matching condition, calculated according to:

$$
k=2 \gamma P_{0}\left(1-f_{R}\right)+2 \sum_{m=1}^{\infty} \frac{\beta_{2 m}}{(2 m)} \omega^{2 m}
$$

is satisfied for this fiber for pump wavelengths from below 1,200 $\mathrm{nm}$ to over $1,700 \mathrm{~nm}$. Resulting phase matching curves for a degenerate FWM process are shown in Fig. 7 for a peak power $\mathrm{P}_{0}$ corresponding to in-coupled energy of $1 \mathrm{~nJ}$, which is roughly what we estimate from coupling efficiency measurement. For supercontinuum pump wavelength of $1,500 \mathrm{~nm}$, degenerate FWM is phase-matched for parametric wavelengths at around 1,250 and $1,900 \mathrm{~nm}$, the latter falling already into anomalous dispersion. For FWM pump wavelengths at 

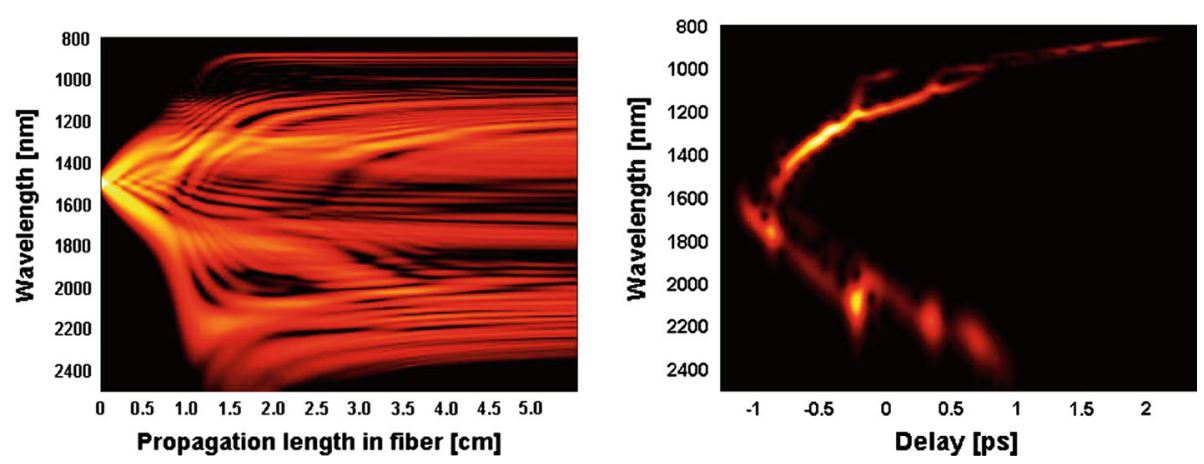

Fig. 6 Simulated evolution of supercontinuum spectrum along the fiber length (left) and corresponding spectrogram

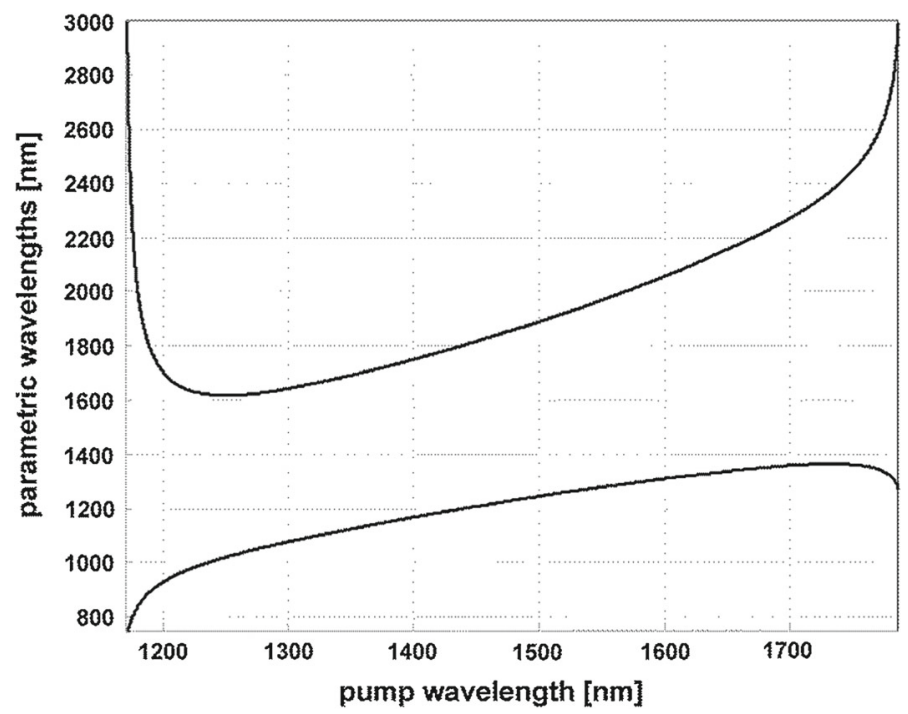

Fig. 7 Four-wave mixing phase matching curves calculated for in-coupled pump pulse energy of $1 \mathrm{~nJ}$

around 1,700 $\mathrm{nm}$ and longer, Stokes parametric wavelengths reach to over 2,500 nm providing ample bandwidth for redshifting solitons. Anti-Stokes FWM wavelengths generated in the normal dispersion, will interfere with SPM wavelengths in that spectral area; spectral beating also occurs between solitons in the long-wavelength, trailing edge of spectrum, and normal dispersion, short-wavelength trailing edge of spectrum (spectrogram in Fig. 6). Broadening dynamics in the fiber is therefore typical to a noise-driven supercontinuum (Dudley et al. 2006).

\section{Summary}

We designed and fabricated new photonic crystal fiber with a suspended core, using inhouse synthesized lead-bismuth-galate oxide glass. We verified experimentally the fiber's suitability for supercontinuum generation. Physical dispersion profile of drawn fiber had first 
ZDW at around 1,600 $\mathrm{nm}$, which was longer, that designed, and limited range of generated spectrum, since disposed pumping at 1,500 $\mathrm{nm}$ fell into normal dispersion range. Despite this, generated bandwidth of $800-2,600 \mathrm{~nm}$, obtained under $70 \mathrm{fs}$ pulses, is encouraging and makes the fiber an attractive platform for further development. This would specifically include improvement of dispersion control and purification of $\mathrm{OH}^{-}$contamination during glass synthesis and fiber drawing, which combined gives potential for extending spectrum generated in this fiber towards the mid-infrared.

Acknowledgments This work was supported in part by the project operated within the Foundation for Polish Science Team Programme co-financed by the European Regional Development Fund, Operational Program Innovative Economy 2007-2013, and in part by research Grant N N515 523738 of Polish Ministry of Science and Higher Education.

Open Access This article is distributed under the terms of the Creative Commons Attribution License which permits any use, distribution, and reproduction in any medium, provided the original author(s) and the source are credited.

\section{References}

Agger, C., Petersen, Ch., Dupont, S., Steffensen, H., Lyngs $\emptyset$, J.K., Thomsen, C.L., Thøgersen, J., Keiding, S.R., Bang, O.: Supercontinuum generation in ZBLAN fibers-detailed comparison between measurement and simulation. J. Opt. Soc. Am. B 29, 635-645 (2012)

Domachuk, P., Wolchover, N.A., Cronin-Golomb, M., Wang, A., George, A.K., Cordeiro, C.M.B., Knight, J.C., Omenetto, F.G.: Over $4000 \mathrm{~nm}$ bandwidth of Mid-IR supercontinuum generation in sub-centimeter segments of highly nonlinear tellurite PCFs. Opt. Express 16, 7161-7168 (2008)

Dong, L., Thomas, B.K., Fu, L.: Highly nonlinear silica suspended core fibers. Opt. Express 16, 16423-16430 (2008)

Dudley, J.M., Taylor, J.R. (eds.) Supercontinuum Generation in Optical Fibers, (Cambridge 2010), Chap. 3.

Dudley, J.M., Genty, G., Coen, S.: Supercontinuum generation in photonic crystal fiber. Rev. Mod. Phys. 78, 1135-1184 (2006)

El-Amraoui, M., Fatome, J., Jules, J.C., Kibler, B., Gadret, G., Fortier, C., Smektala, F., Skripatchev, I., Polacchini, C.F., Messaddeq, Y., Troles, J., Brilland, L., Szpulak, M., Renversez, G.: Strong infrared spectral broadening in low-loss As-S chalcogenide suspended core microstructured optical fibers. Opt. Express 18, 4547-4556 (2010)

Ertman, S., Tefelska, M., Chylowski, M., Rodriquez, A., Pysz, D., Buczynski, R., Nowinowski-Kruszelnicki, E., Dabrowski, R., Wolinski, T.R.: Index guiding photonic liquid crystal fibers for practical applications. J. Lightwave Technol. 30, 1208-1214 (2012)

Fu, L., Thomas, B.K., Dong, L.: Efficient supercontinuum generations in silica suspended core fibers. Opt. Express 16, 19629-19642 (2008)

Guo, B., Wang, Y., Peng, C., Zhang, H.L., Luo, G.P., Le, H.Q., Gmachl, C., Sivco, D.L., Peabody, M.L., Cho, A.Y.: Laser-based mid-infrared reflectance imaging of biological tissues. Opt. Express 12(1), 208-219 (2004)

Kaminski, C.F., Watt, R.S., Elder, A.D., Frank, J.H., Hult, J.: Supercontinuum radiation for applications in chemical sensing and microscopy. Appl. Phys. B: Lasers Opt. 92, 367-378 (2008)

Lorenc, D., Aranyosiova, M., Buczynski, R., Stepien, R., Bugar, I., Vincze, A., Velic, D.: Nonlinear refractive index of multicomponent glasses designed for fabrication of photonic crystal fibers. Appl. Phys. B 93, 531-538 (2008)

Marandi, A., Rudy, C.W., Leindecker, N.C., Plotnichenko, V.G., Dianov, E.M., Vodopyanov, K.L., Byer, R.L.: Mid-infrared supercontinuum generation from $2.4 \mu \mathrm{m}$ to $4.6 \mu \mathrm{m}$ in tapered chalcogenide fiber. Conference on Lasers and Electro-Optics, CLEO 2012, art. no. 6325931

Mergo, P., Makara, M., Wojcik, J., Poturaj, K., Klimek, J., Skorupski, K., Nasilowski, T.: Supercontinuum generation in suspended core microstructured optical fibers. Proc. SPIE 7120, 712009 (2008)

Savelii, I., Jules, J.C., Gadret, G., Kibler, B., Fatome, J., El-Amraoui, M., Manikandan, N., Zheng, X., Désévédavy, F., Dudley, J.M., Troles, J., Brilland, L., Renversez, G., Smektala, F.: Suspended core tellurite glass optical fibers for infrared supercontinuum generation. Opt. Mater. 33, 1661-1666 (2011) 
Savelii, I., Mouawad, O., Fatome, J., Kibler, B., Désévédavy, F., Gadret, G., Jules, J.-C., Bony, P.-Y., Kawashima, H., Gao, W., Kohoutek, T., Suzuki, T., Ohishi, Y., Smektala, F.: Mid-infrared 2000-nm bandwidth supercontinuum generation in suspended-core microstructured Sulfide and Tellurite optical fibers. Opt. Express 20, 27083-27093 (2012)

Savelii, I., Desevedavy, F., Jules, J-Ch., Gadret, G., Fatome, J., Kibler, B., Kawashima, H., Ohishi, Y., Smektala, F.: Management of $\mathrm{OH}$ absorption in tellurite optical fibers and related supercontinuum generation. Opt. Mater. 35, 1595-1599 (2013)

Stepien, R., Pysz, D., Kujawa, I., Pniewski, J., Waddie, A.J., Taghizadeh, M.R., Buczynski, R.: Development of large-core photonic crystal fiber for hyperspectral transmission. Proc. SPIE 8426, 842614 (2012)

Swiderski, J., Maciejewska, M.: Watt-level, all-fiber supercontinuum source based on telecom-grade fiber components. Appl. Phys. B 109, 177-181 (2012)

Unterhuber, A., Považay, B., Bizheva, K., Hermann, B., Sattmann, H., Stingl, A., Le, T., Seefeld, M., Menzel, R., Preusser, M., Budka, H., Schubert, Ch., Reitsamer, H., Ahnelt, P.K., Morgan, J.E., Cowey, A., Drexler, W.: Advances in broad bandwidth light sources for ultrahigh resolution optical coherence tomography. Phys. Med. Biol. 49, 1235-1246 (2004)

Waynant, R., Ilev, I., Gannot, I.: Mid-infrared laser applications in medicine and biology. Philos. Trans. R. Soc. Lond. A 359, 635-644 (2001)

Werle, P., Slemr, F., Maurera, K., Kormannb, R., Muckec, R., Jankerd, B.: Near- and mid-infrared laser-optical sensors for gas analysis. Opt. Lasers Eng. 37, 101-114 (2002) 